\title{
Editorial
}

\section{A resposta da administração pública brasileira aos desafios da pandemia}

\section{Alketa Peci ${ }^{1}$}

${ }^{1}$ Fundação Getulio Vargas / Escola Brasileira de Administração Pública e de Empresas, Rio de Janeiro / RJ - Brasil

A chamada especial de trabalhos organizada pela Revista de Administração Pública visou mobilizar pesquisadores a responderem aos desafios concretos impostos pela pandemia à administração pública brasileira. Os números de submissão são um claro indicador da mobilização inédita em torno da chamada: 211 submissões que abrangeram 613 pesquisadores e 185 instituições de pesquisa. Deste total, 289 artigos foram submetidos por mulheres. Contamos com a colaboração de uma rede de 104 avaliadores, além do corpo editorial, para possibilitar um processo tempestivo de respostas às demandas sociais em curso. Foram aceitos 17\% dos trabalhos submetidos, representando 41 instituições acadêmicas e 105 autores, dos quais apenas 39 mulheres, corroborando os resultados do relatório da Parents in Science (2020) sobre o impacto negativo da COVID-19 na produtividade acadêmica das pesquisadoras.

A pandemia da COVID-19 caracteriza-se como uma crise extrema, definida por uma percepção generalizada de ameaça aos valores ou funções fundamentais de um sistema social, demandando ações urgentes em circunstâncias incertas (Rosenthal, Charles, \& Hart, 1989). A pandemia ameaça valores centrais das sociedades modernas, como se evidencia no debate "vidas versus economia", e a complexidade da situação torna desafiador, para qualquer governo, o desenho de estratégias claras para o seu enfrentamento. Entretanto, em contextos deste tipo, os governos devem responder com firmeza e demonstrar liderança (Christensen, Lægreid, \& Rykkja, 2016). Capacidades estatais existentes, a exemplo da musculatura de sistemas de saúde vigentes, têm sido destacadas pela sua relevância nas respostas governamentais à pandemia (Capano et al., 2020; Weible et al., 2020).

De uma perspectiva comparativa, esperava-se que o Brasil entraria na pandemia numa posição relativamente melhor em termos de capacidades estatais já existentes, particularmente atribuídas ao nosso sistema único de saúde (SUS). Sendo uma estrutura federativa e interorganizacional complexa, o SUS, apesar de variados problemas, tem construído capacidade de coordenação e aprendizagem no combate de epidemias como H1N1 ou Zica (Croda et al., 2020). No entanto, os dados brasileiros de infecção e óbitos decorrentes da COVID-19, que em 2 de agosto de 2020 apontam mais de 94 mil óbitos, frustraram esta expectativa.

Esta chamada especial reúne 35 trabalhos, agrupados em torno de seis temas transversais que buscam integrar as respostas da administração pública aos desafios complexos impostos pela pandemia. Nestes trabalhos, a administração pública emerge não apenas como um espaço de tomada de decisão, mas também como um lócus de conflitos distributivos e morais impostos pela natureza da crise e por seu ineditismo. 
O primeiro conjunto de trabalhos apresenta uma análise e reflexão sobre as atuais capacidades estatais e seu potencial na gestão da crise, não apenas restritas à área de saúde, mas incluindo o aparato estatal de forma mais abrangente. No seu conjunto, os estudos ajudam a identificar as fragilidades e vulnerabilidades das capacidades estatais necessárias à gestão da crise. Paralelamente, os pesquisadores indicam formas de mobilizar o aparato estatal, cujo papel é inquestionável na superação dos desafios impostos pela pandemia.

O segundo conjunto de trabalhos diz respeito às respostas comportamentais à pandemia, explorando as peculiaridades do contexto brasileiro. Os trabalhos indicam uma série de fatores que influenciam a predisposição ao isolamento social, como polarização política e normas subjetivas. A liderança política surge como outro fator primordial que desponta na gestão das crises (Boin etal., 2010; Boin, 't Hart, McConnell, \& Preston, 2010; Kapucu, 2006). Neste ponto, o Brasil tem se evidenciado como um caso problemático de exercício da liderança na esfera política, particularmente em um contexto de excessiva polarização. Um dos papéis fundamentais da liderança é promover uma compreensão social compartilhada da pandemia via uma comunicação eficaz. De forma geral, as pesquisas destacam a importância das estratégias de comunicação da liderança na influência das reações emocionais do público, bem como das percepções da eficácia do governo ao lidar com asituação.

Um terceiro conjunto de trabalhos dedica-se ao exame das estratégias de enfrentamento da pandemia adotadas pelo setor público. As pesquisas identificam caminhos adotados pelas prefeituras para reduzir a transmissão da COVID-19 durante o estágio inicial crítico, orientando a formulação de políticas. A análise das áreas meio e de diversas organizações da administração pública revela como estas mobilizam-se no contexto da pandemia, identificando diversas falhas de coordenação, outro ponto central para a gestão das crises (Christensen, Lægreid, \& Rykkja, 2016). Todas estas estratégias devem ser vistas à luz dos dilemas morais que gestores públicos enfrentam neste contexto. A crise afasta cidadãos e gestores públicos do status quo, exigindo o desenvolvimento de novas formas de raciocínio moral, principalmente em relação às obrigações sociais e morais dos governos e aos limites dessa interferência no direito individual dos cidadãos.

A capacidade de mobilização das organizações da sociedade civil (OSCs), imposta pela situação extrema que se instaurou com a pandemia da COVID-19, é discutida em dois estudos do número especial. Os pesquisadores discutem as características das OSCs que as habilitam a contribuir para as medidas de emergência adotadas pelos governos e a possibilidade de ampliação dos arranjos colaborativos entre governos e OSCs. As investigações permitem construir um panorama da ação dessas "redes invisíveis" de colaboração e lançar pistas sobre consequências e desafios dessa atuação.

Os efeitos da pandemia não se limitam apenas à área de saúde pública, conforme expõe outro tema dedicado a este assunto. Nestas pesquisas são discutidos e mensurados os efeitos da pandemia na política, no mercado de trabalho, na educação básica, em setores de prestação de serviços públicos e nas micro e pequenas empresas.

Por fim, a crise gerada pela COVID-19 já indica que seus efeitos não se estendem uniformemente a todos os segmentos da sociedade. As vulnerabilidades sociais demandam estratégias sofisticadas de ação pública que busquem evitar o retorno a índices alarmantes de pobreza e desigualdade social. Os trabalhos não apenas diagnosticam estas vulnerabilidades, mas também apresentam uma análise a respeito de como medidas concretas, como o auxílio emergencial, instituído pela Lei no 13.982 (2020), e programas já existentes, a exemplo do Bolsa Família ou do recurso a moedas digitais complementares, podem ser utilizados para minimizar os impactos do momento adverso para segmentos mais vulneráveis da população brasileira. Pesquisadores também recorrem ao uso de dinâmica de sistemas para apoiar decisões de políticas públicas relativas a medidas que têm por objetivo aliviar os efeitos negativos da disseminação do vírus em favelas. 
O número especial finaliza com uma reflexão sobre os desafios econômicos, tecnológicos, sociais e geopolíticos no cenário pós-COVID-19, convidando a academia a uma necessária reflexão sobre estratégias de longo prazo, que demandarão a revisão dos atuais paradigmas educacionais, sociais e políticos.

A crise desencadeada pela COVID-19 evidencia a centralidade do papel do Estado na gestão da pandemia. Os trabalhos aqui reunidos detectam vulnerabilidades em capacidades estatais existentes, ao exemplo do SUS, mas também identificam potencialidades em diversas áreas de políticas públicas e decisões governamentais. Esperamos que este conjunto de reflexões subsidie, com evidências, os processos de tomada de decisão no contexto da pandemia e demarque, no âmbito da administração pública brasileira, o potencial da contribuição da pesquisa acadêmica na gestão da crise e de suas consequências.

\section{REFERÊNCIAS}

Boin, A., \& 't Hart, P. (2003). Public leadership in times of crisis: mission impossible? Public Administration Review, 63(5), 544-553.

Boin, A., 't Hart, P. T., McConnell, A., \& Preston, T. (2010). Leadership style, crisis response and blame management: The case of Hurricane Katrina. Public Administration, 88(3), 706-723.

Capano, G., Howlett, M., Jarvis, D. S., Ramesh, M., \& Goyal, N. (2020). Mobilizing Policy (In) Capacity to Fight COVID-19: Understanding Variations in State Responses. Policyand Society,39(3),285-308.

Christensen, T., Lægreid, P., \& Rykkja, L. H. (2016). Organizing for crisis management: Building governance capacity and legitimacy. Public Administration Review, 76(6), 887-897.

Kapucu, N. (2006). Interagency communication networks during emergencies: Boundary spanners in multiagency coordination. The American Review of Public Administration, 36(2),207-225.

Lei $n^{\circ}$ 13.982, de 2 de abril de 2020. (2020). Altera a Lei no 8.742 , de 7 de dezembro de 1993, para dispor sobre parâmetros adicionais de caracterização da situação de vulnerabilidade social para fins de elegibilidade ao benefício de prestação continuada (BPC), e estabelece medidas excepcionais de proteção social a serem adotadas durante o período de enfrentamento da emergência de saúde pública de importância internacional decorrente do coronavírus (Covid-19) responsável pelo surto de 2019, a que se refere a Lei $\mathrm{n}^{\mathrm{o}}$ 13.979, de 6 de fevereiro de 2020. Recuperado de http://www.planalto.gov.br/ccivil_03/_ato20192022/2020/lei/113982.htm

Parents in Science. (2020). Produtividade acadêmica durante a pandemia: Efeitos de gênero, raça e parentalidade. (pp. 1-13, Rep.). Porto Alegre, RS: Autor. Recuperado dehttps://327b604e-5cf4-492b-910b-e35e2bc67511.filesusr.com/ugd/0b341b_81cd8390d0f94bfd8fcd17ee6f29bc0e.pdf?index =true

Rosenthal, U., Charles, M. T., \& Hart, P. T. (Eds.). (1989).Copingwithads: Themanagementofdisas- ters, riots, and terrorism. Springfield, Illinois: Charles C Thomas Pub Ltd.

Weible, C. M., Nohrstedt, D., Cairney, P., Carter, D. P., Crow, D. A., Durnová, A. P., ... Stone, D. (2020). COVID-19 and the policy sciences: initial reactions and perspectives. Policy sciences, 53, 225-241.

\section{Alketa Peci}

https://orcid.org/0000-0002-0488-1744

Doutora em Administração e professora associada da Escola Brasileira de Administração Pública e de Empresas da Fundação Getulio Vargas; Editora-chefe da Revista de Administração Pública (RAP).

E-mail: alketa.peci@fgv.br 